\title{
"Para o Infinito e Além!"
}

\author{
Áurea J. Chaves
}

"P ara o infinito e além!", citação de personagem de conhecido filme de animação computadorizada*, refletiu com nitidez o estado de espírito das pessoas envolvidas no processo de indexação da Revista Brasileira de Cardiologia Invasiva (RBCI) no SciELO (Scientific Electronic Library Online), ao saberem da aprovação da Revista, neste mês de dezembro.

A indexação no SciELO, alcançada anualmente por poucos periódicos, é um reconhecimento da qualidade científica da Revista e foi conseguida depois de cumprirmos rigorosos requisitos de forma e conteúdo. A indexação aumentará significantemente a visibilidade da $\mathbf{R B C I}$, visto que o SciELO é uma base de dados bastante consultada, e elevará nossa classificação no Qualis Periódicos da CAPES, atraindo a produção científica proveniente de programas de mestrado e doutorado.

Essa conquista foi alcançada por um verdadeiro trabalho de equipe, em que vários membros da $\mathrm{SBHCl}$ atuaram incansavelmente na busca desse objetivo comum. Os esforços foram iniciados em 2007, com a estratégia visionária de Luiz Alberto Mattos e a parceria fundamental com Rogério Sarmento-Leite e, mais recentemente, Alexandre Quadros. Nesse período, a equipe ganhou reforço considerável, com importante atuação de Antonio Carlos Carvalho, Carlos Pedra, José Antonio Marin-Neto, Marcelo Cantarelli, Marcelo Queiroga e Maurício Barbosa.

A indexação no SciELO não seria conseguida sem a participação fundamental de autores, revisores e componentes do Corpo Editorial, que dedicaram esforços e seu tempo na construção da Revista, considerada, em pesquisa recente, entre os 50 principais formadores de opinião da $\mathrm{SBHCl}$, seu bem mais valioso.

Planejamos para o próximo biênio, com o apoio das Diretorias da SBHCl, atual e eleita para 2012-2013, a versão completa da $\mathbf{R B C I}$ em inglês e a preparação da Revista para as exigências ainda maiores para a indexação no Medline.

A edição atual traz, como um de seus destaques, o Registro BRAVO, que avaliou o desempenho do stent liberador de everolimus no tratamento de pacientes minimamente selecionados da prática clínica nacional. Abreu-Silva, da Escola Paulista de Medicina (São Paulo, SP), e demais colaboradores desse estudo multicêntrico traçam o complexo perfil clínico e angiográfico dos pacientes e expõem as características detalhadas do procedimento e os resultados clínicos em seis meses, que incluem as taxas de aderência ao regime antiplaquetário duplo e da trombose do stent. Em editorial relacionado, Claessen, da Universidade de Amsterdã (Amsterdã, Holanda), e Mehran e Stone, da Cardiovascular Research Foundation (Nova York, Estados Unidos), põem em perspectiva os resultados dos stents farmacológicos de segunda geração, a importância dos registros clínicos de alta qualidade, que complementam os achados dos estudos randomizados, e os desafios que os novos stents farmacológicos enfrentarão ao tentar superar os notáveis resultados clínicos dos stents liberadores de everolimus.

Dando sequência a uma série de artigos que avaliam o desempenho da prótese aórtica CoreValve ${ }^{\mathrm{TM}}$ (Medtronic, Minneapolis, Estados Unidos) publicada na $\mathbf{R B C I}$, Bernardi e colaboradores, do Instituto de Cardiologia do Rio Grande do Sul (Porto Alegre, RS), trazem os resultados do implante valvular aórtico percutâneo sem pré-dilatação. Trata-se de estratégia que visa a reduzir as complicações embólicas relacionadas ao implante, bem como os distúrbios de condução atrioventriculares associados e a necessidade de implante de marca-passo definitivo. Magalhães, do Hospital Alemão Oswaldo Cruz (São Paulo, SP), e Grube, do Hospital Alemão Oswaldo Cruz (São Paulo, SP) e do Hospital Universitário de Bonn (Bonn, Alemanha), este último precursor da estratégia, comentam em seu editorial as vantagens e as desvantagens da pré-dilatação, etapa da técnica atual de implante, e a necessidade de estudos randomizados para confirmar ou não a eliminação dessa etapa.

Em outro artigo de interesse, Lima e colaboradores, do Hospital Madre Teresa (Belo Horizonte, MG), abordam os resultados, pouco explorados na literatura nacional, da intervenção coronária percutânea pós-fibrinólise, realizada em centro de referência da região metropolitana de Belo Horizonte. O Registro do Hos-

* Buzz Lightyear, em "Toy Story" (๔ Disney Enterprises, Inc. and Pixar Animation Studios - 2005). 
pital Madre Teresa traz o perfil dos pacientes tratados, os trombolíticos escolhidos, o tempo de transferência e os stents empregados, e mostra os resultados clínicos e preditores independentes de eventos cardíacos adversos maiores hospitalares. Quadros, do Instituto de Cardiologia do Rio Grande do Sul (Porto Alegre, RS), em editorial correspondente, faz revisão didática das indicações de intervenção coronária percutânea pós-trombólise, baseado na ACCF/AHA/SCAI Guideline for Percutaneous Coronary Intervention, publicada online em novembro de 2011, avalia os resultados do Registro dentro da realidade de atendimento pelo Sistema Único de Saúde (SUS) e traz, ao final, notícias animadoras, com o lançamento de programas do Ministério da Saúde para Protocolo de Trombólise no SUS e para Estímulo das Unidades Coronárias, que certamente irão qualificar o atendimento do paciente com infarto agudo do miocárdio no setor público.

Para finalizar, gostaria de agradecer ao presidente da SBHCl Maurício Barbosa, ao diretor administrativo Marcelo Cantarelli e ao diretor de Comunicação Alexandre Quadros a parceria nessa jornada vitoriosa da $\mathbf{R B C I}$, e saudar o novo presidente eleito Marcelo Queiroga e demais diretores, que têm entre suas propostas administrativas o contínuo estímulo ao crescimento da Revista.

Feliz 2012!

Áurea J. Chaves

Editora 